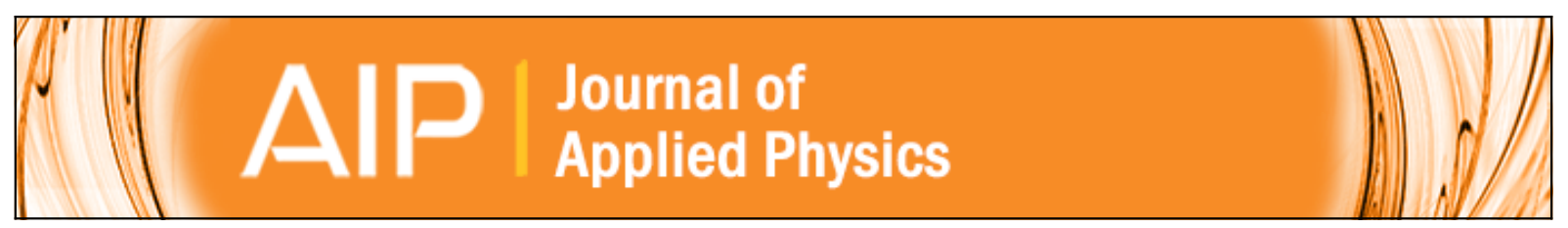

\title{
Barium depletion in hollow cathode emitters
}

James E. Polk, loannis G. Mikellides, Angela M. Capece, and Ira Katz

Citation: Journal of Applied Physics 119, 023303 (2016); doi: 10.1063/1.4938489

View online: http://dx.doi.org/10.1063/1.4938489

View Table of Contents: http://scitation.aip.org/content/aip/journal/jap/119/2?ver=pdfcov

Published by the AIP Publishing

\section{Articles you may be interested in}

Barium strontium oxide coated carbon nanotubes as field emitters

Appl. Phys. Lett. 90, 143114 (2007); 10.1063/1.2719645

Composite-layered solid-state field controlled emitter for a better control of the cathode surface barrier J. Vac. Sci. Technol. B 23, 824 (2005); 10.1116/1.1864065

Transition metal carbide field emitters for field-emitter array devices and high current applications J. Vac. Sci. Technol. B 17, 613 (1999); 10.1116/1.590605

Effect of $\mathrm{CH} 4$ on the electron emission characteristics of active molybdenum field emitter arrays J. Vac. Sci. Technol. B 16, 3073 (1998); 10.1116/1.590444

Effects of thermal annealing on emission characteristics and emitter surface properties of a Spindt-type field emission cathode

J. Vac. Sci. Technol. B 16, 783 (1998); 10.1116/1.590218

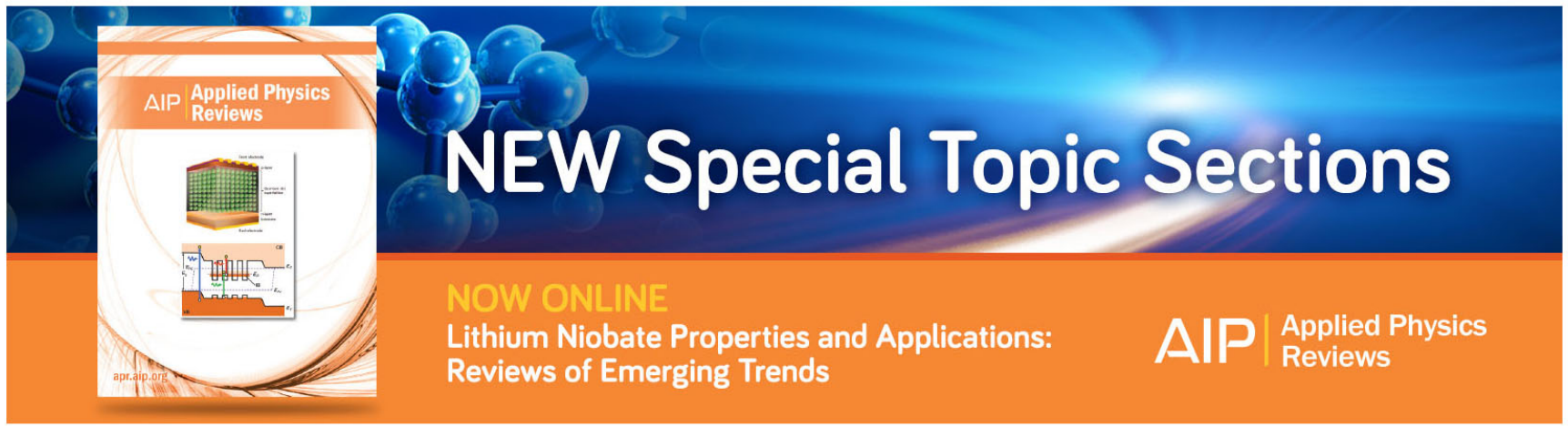




\title{
Barium depletion in hollow cathode emitters
}

\author{
James E. Polk, ${ }^{1, a)}$ Ioannis G. Mikellides, ${ }^{1}$ Angela M. Capece, ${ }^{2, b)}$ and Ira Katz ${ }^{1}$ \\ ${ }^{1}$ Jet Propulsion Laboratory, California Institute of Technology, Pasadena, California 91109, USA \\ ${ }^{2}$ Graduate Aerospace Laboratories, California Institute of Technology, Pasadena, California 91125, USA
}

(Received 25 July 2015; accepted 10 December 2015; published online 11 January 2016)

\begin{abstract}
Dispenser hollow cathodes rely on a consumable supply of Ba released by $\mathrm{BaO}-\mathrm{CaO}-\mathrm{Al}_{2} \mathrm{O}_{3}$ source material in the pores of a tungsten matrix to maintain a low work function surface. The examination of cathode emitters from long duration tests shows deposits of tungsten at the downstream end that appear to block the flow of $\mathrm{Ba}$ from the interior. In addition, a numerical model of $\mathrm{Ba}$ transport in the cathode plasma indicates that the $\mathrm{Ba}$ partial pressure in the insert may exceed the equilibrium vapor pressure of the dominant Ba-producing reaction, and it was postulated previously that this would suppress Ba loss in the upstream part of the emitter. New measurements of the Ba depletion depth from a cathode insert operated for $8200 \mathrm{~h}$ reveal that $\mathrm{Ba}$ loss is confined to a narrow region near the downstream end, confirming this hypothesis. The Ba transport model was modified to predict the depletion depth with time. A comparison of the calculated and measured depletion depths gives excellent qualitative agreement, and quantitative agreement was obtained assuming an insert temperature $70^{\circ} \mathrm{C}$ lower than measured beginning-of-life values. C 2016 AIP Publishing LLC. [http://dx.doi.org/10.1063/1.4938489]
\end{abstract}

\section{INTRODUCTION}

State-of-the-art hollow cathodes used in ion and Hall thrusters consist of a porous tungsten tube (the "insert"), which is contained in a refractory metal cathode tube with an orifice plate on the downstream end. A small fraction of the thruster propellant is injected through the hollow cathode, and the orifice serves to increase the internal pressure in the insert region. Electron emission from the inner surface maintains an internal plasma which heats the insert to the required operating temperature and helps conduct the current into the main discharge. A heater surrounding the cathode is used to preheat it prior to ignition.

A low emitter operating temperature is achieved by maintaining a layer of adsorbed oxygen and barium atoms that reduces the surface work function. In state-of-the-art impregnated cathodes $\mathrm{Ba}$ and $\mathrm{BaO}$ are supplied by $\mathrm{BaO}-$ $\mathrm{CaO}-\mathrm{Al}_{2} \mathrm{O}_{3}$ source material (the "impregnant") incorporated in the pores of the tungsten. Gaseous $\mathrm{Ba}$ and $\mathrm{BaO}$ are released in interfacial reactions between the tungsten matrix and the impregnant, producing a temperature-dependent vapor pressure of these species inside the pores. $\mathrm{Ba}$ and $\mathrm{BaO}$ then migrate to the surface by Knudsen flow and surface diffusion on the pore walls. In vacuum dispenser cathodes, $\mathrm{Ba}$ adsorbates lost by evaporation are replenished by $\mathrm{Ba}$ and $\mathrm{BaO}$ through surface diffusion from the pores and most of the vapor flow from the pores is lost. In gas discharges, the vapor in the discharge may be transported back to the cathode surface, offering another path for replenishing Ba lost by desorption.

Near the surface, volatile products of the impregnant reactions escape to the exterior through the pores, allowing

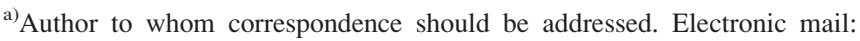
james.e.polk@jpl.nasa.gov

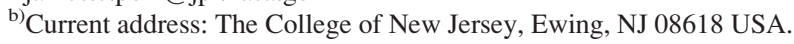

the reactions to proceed to completion. Eventually, relatively stable tungstates are produced and production of volatile species in that region ceases. The reaction front proceeds deeper into the insert as reactants nearer the surface are consumed and the porosity of the impregnant increases due to loss of volatile materials. The region behind the reaction front is depleted of $\mathrm{Ba}$ and the depth of this depletion layer has been characterized in some cathode tests ${ }^{1}$ as an indicator of cathode life.

Insert life is ultimately limited by the Ba supply in the impregnant. When the supply rate from the interior or from the gas phase drops below the rate at which adsorbed atoms are lost from the surface by desorption, the surface coverage drops and the work function rises. ${ }^{2}$ The cathode eventually becomes impossible to ignite or cannot be heated to the temperatures needed for the required electron current density.

A combination of experiments and modeling is being used to develop the analytical capability to assess cathode failure risk due to Ba depletion. In previous work ${ }^{3,4}$ detailed examinations of discharge cathode inserts from two long duration tests were reported. The $8200 \mathrm{~h}$ Life Demonstration Test (LDT) was performed with a $30-\mathrm{cm}$ engineering model ion thruster ${ }^{5}$ similar to that flown on the Deep Space 1 (DS1) mission. ${ }^{6,7}$ A subsequent Extended Life Test (ELT) was performed with the DS1 flight spare thruster, ultimately accumulating $30352 \mathrm{~h}$ of operation. ${ }^{8}$ Analysis of these inserts revealed dense deposits of tungsten at the downstream end of the insert and evidence that they blocked off the pores and prevented flow of $\mathrm{Ba}$ from under the zone responsible for most of the electron emission. ${ }^{3}$ Despite this, the cathodes operated properly and exhibited no evidence of performance degradation. Similar tungsten transport has been observed in many extended hollow cathode tests. ${ }^{2,5,9,10}$

A model of $\mathrm{Ba}$ transport in the hollow cathode plasma ${ }^{3}$ showed that $\mathrm{Ba}$ is effectively recycled in the discharge. $\mathrm{Ba}$ 
emitted from the upstream surfaces of the insert is ionized in the intense Xe plasma and pushed to the downstream surfaces by the electric field. An unexpected result of the model was that over much of the insert length the neutral Ba partial pressure exceeds the equilibrium pressure of the dominant Ba-producing reaction. We proposed that this would suppress the impregnant decomposition reactions in these areas and prevent $\mathrm{Ba}$ loss from the interior. The model predicted that $\mathrm{Ba}$ was only supplied to the discharge from a narrow region just upstream of the tungsten deposits blocking flow in the electron emission zone.

In this paper, we present new experimental results from further examination of the LDT discharge cathode confirming that $\mathrm{Ba}$ depletion occurs only in this narrow region. Predictions of the depletion depth based on an improved version of the $\mathrm{Ba}$ transport model are compared with the measured values.

\section{EXPERIMENTAL CHARACTERIZATION OF BARIUM DEPLETION}

The discharge cathode operated for a total of $8200 \mathrm{~h}$ at a Xe flow rate of $3.7 \mathrm{sccm}$ and a current that ranged from 13 to 15.2 A. Details of the post-test analyses of the insert and cathode assembly were reported previously. ${ }^{3,5}$ Here, we summarize the key observations and report new measurements of the Ba depletion depth as a function of position along the emitter.

Changes in the emitter geometry were characterized with laser profilometry and imaging in a scanning electron microscope (SEM). The LDT discharge cathode profile exhibited erosion of the inner wall over $15 \mathrm{~mm}$ at the downstream end, with more severe erosion in the first 4-5 $\mathrm{mm}$. Up to $100 \mu \mathrm{m}$ of the tungsten matrix were lost at the downstream end. SEM photomicrographs of the emitter surface also showed a combination of erosion and redeposition of tungsten in the downstream regions of the insert. A dense growth of vapor-deposited tungsten crystals covered the tungsten pores at the downstream end. Tungsten deposits were found in the surface pores over the rest of the eroded region, although it is not clear from the SEM images if these deposits closed off the pores.

Quantitative measurements of Ba depletion depths were obtained using energy dispersive spectroscopy (EDS) of individual impregnant grains visible in the polished cross section of the LDT discharge cathode emitter. Figure 1 shows a photomicrograph of an area near the emitter surface. The insert manufacturing process includes a weak etch after impregnation to remove impregnant from the surface and pores near the surface. The open pores visible in the top half of the image indicate this impregnant-free etched zone. In the lower half, the pores are filled with impregnant material.

The concentration of $\mathrm{Al}$ remains relatively constant over the insert interior because $\mathrm{Al}$ in the impregnant does not form volatile reaction products. It can therefore be used as an internal standard to determine relative concentrations of $\mathrm{Ba}$ and $\mathrm{Ca}$. Regions that are depleted of $\mathrm{Ba}$ and $\mathrm{Ca}$ will have lower ratios of the $\mathrm{Ba}$ or $\mathrm{Ca}$ peak area to the $\mathrm{Al}$ peak area as
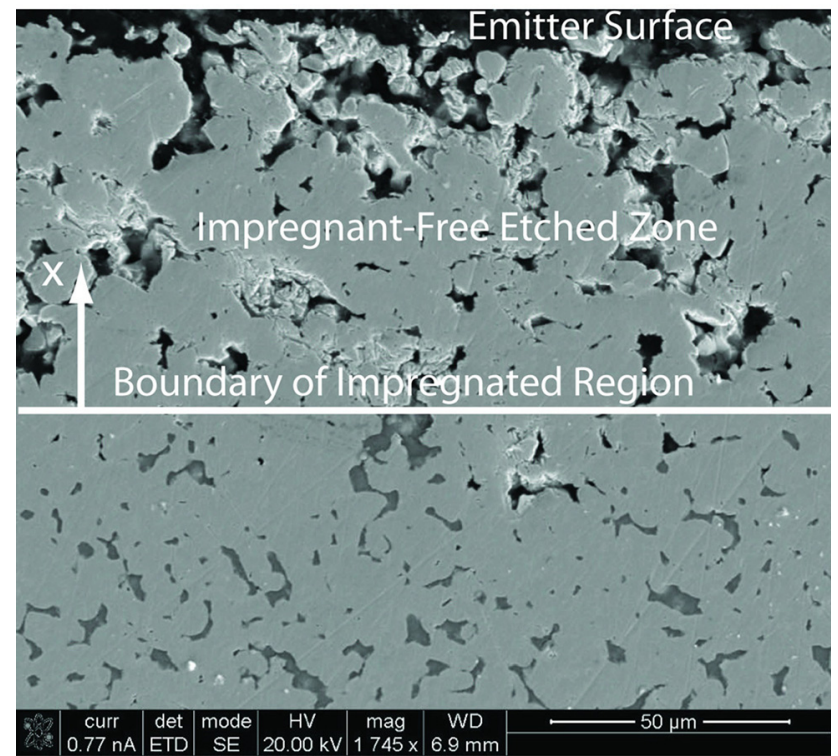

FIG. 1. Photomicrograph of the insert cross section showing pores containing impregnant material (bottom of image) and the impregnant-free etched zone near the surface (top of image).

compared with regions with unreacted impregnant. The difference is quite obvious, as shown in Fig. 2. Regions in individual impregnant grains were identified on the SEM images, and EDS spectra were obtained for those areas. Peak areas for the dominant $\mathrm{Ba}, \mathrm{Ca}$, and $\mathrm{Al}$ lines in the spectra were calculated and used to form the ratios, which were then plotted as a function of the depth of the impregnant grain below the boundary defining the edge of the impregnated zone.

In this example, grains deeper than about $40 \mu \mathrm{m}$ from the edge of the etch zone have $\mathrm{Ba} / \mathrm{Al}$ ratios of about 2.5 and $\mathrm{Ca} / \mathrm{Al}$ ratios of 0.29 . Grains near the etched zone have corresponding ratios of 0.75 and zero, reflecting a loss of volatile $\mathrm{Ba}$ and $\mathrm{Ca}$ reaction products. In some locations, the $\mathrm{Ca} / \mathrm{Al}$ ratios in the interior were as high as 0.6 , perhaps reflecting a nonuniform distribution of free $\mathrm{CaO}$. Examining individual grains at different depths provided a relatively well-defined boundary for the depleted zone. The majority of grains above the boundary exhibited $\mathrm{Ba}$ and $\mathrm{Ca}$ depletion, although

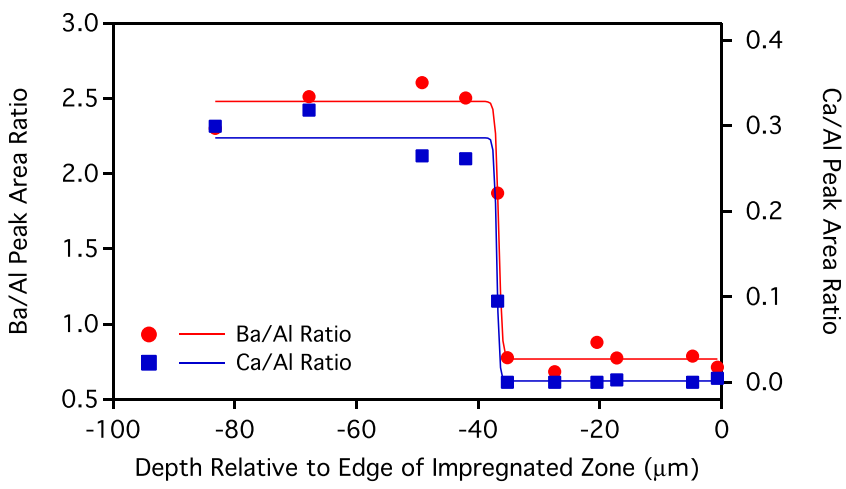

FIG. 2. The boundary between unreacted impregnant and the near-surface depleted layer based on ratios of $\mathrm{Ba}$ and $\mathrm{Ca}$ peak areas to that of $\mathrm{Al}$, which serves as an internal standard. 
isolated exceptions were found, probably in locations which did not have interconnected pores forming a path to the surface.

Figure 3 shows measurements of the thickness of the impregnant-free etched zone and the depth of the depleted zone along the emitter length. The zero line in this plot corresponds to the edge of the impregnated zone. Two notable features are apparent. First, the cathode suffered remarkably little $\mathrm{Ba}$ loss in this test, with a maximum depleted depth of only $50 \mu \mathrm{m}$. Second, the Ba loss is restricted to a fairly narrow region centered at $1.6 \mathrm{~cm}$, about $4 \mathrm{~mm}$ from the downstream end. As argued previously, ${ }^{3}$ the restructuring of the surface at the downstream end appears to reduce the effective porosity, preventing $\mathrm{Ba}$ loss, and the partial pressure of $\mathrm{Ba}$ in the discharge plasma is sufficiently high upstream that it inhibits the impregnant decomposition reactions.

\section{A MODEL OF BARIUM DEPLETION}

The reduction of $\mathrm{Ba}$ flux from the insert by tungsten deposits and the finite $\mathrm{Ba}$ partial pressure are incorporated in a numerical model of $\mathrm{Ba}$ transport in the hollow cathode discharge. This model was used to calculate the net barium flow from the insert and the resulting depletion depth as a function of time to compare with the experimental results. The numerical model of $\mathrm{Ba}$ transport has been described in detail previously, ${ }^{3}$ but the major features will be briefly summarized here. The initial focus of the modeling is on Ba because this is the dominant species produced by the insert. ${ }^{11} \mathrm{Ba}$ transport is strongly influenced by the Xe plasma; the electron density and temperature control the ionization of $\mathrm{Ba}$, and the electric field in the Xe plasma and collisions with Xe and $\mathrm{Xe}^{+}$ions control the diffusion of $\mathrm{Ba}$. However, $\mathrm{Ba}$ atom and ion densities are so low they do not significantly modify the charge density or temperature in what is primarily a Xe discharge. This allows us to separate the problem into two parts and use the major species parameters predicted by a Xe discharge model developed by Mikellides et al. ${ }^{12}$ as fixed quantities in the solution of the minor species transport equations.

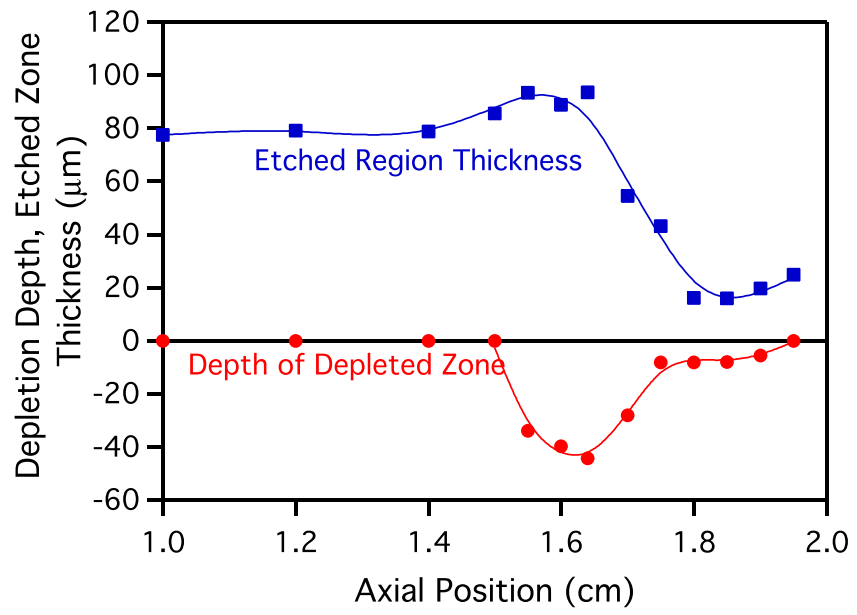

FIG. 3. Measured thickness of the etched layer near the surface and depletion depth in the impregnated region beneath it. The zero line represents the boundary of the impregnated region.

\section{A. Barium transport equations}

The $\mathrm{Ba}$ flow in the insert plasma is modeled using the species momentum and continuity equations. We assume that viscous and magnetic field effects are negligible, that the phenomena of interest are slow, i.e., there are no high frequency phenomena and fluid acceleration is small compared to the force terms, and that collisions between minor species (such as $\mathrm{Ba}-\mathrm{Ba}^{+}$collisions) are sufficiently rare that they can be neglected. The flux of minor species, $j$, can then be written as the sum of four terms,

$$
\begin{aligned}
\boldsymbol{\Gamma}_{j}= & n_{j} \mathbf{u}_{j} \\
= & \frac{-\nabla P_{j}}{\nu_{j, X e^{+}} \mu_{j, X e}\left(1+\nu_{j, X e} / \nu_{j, X e^{+}}\right)}+\frac{e n_{j} \mathbf{E}}{\nu_{j, X e+} \mu_{j, X e}\left(1+\nu_{j, X e} / \nu_{j, X e^{+}}\right)} \\
& +n_{j}\left(\frac{1}{1+\nu_{j, X e} / \nu_{j, X e^{+}}}\right) \mathbf{u}_{X e^{+}}+n_{j}\left(\frac{\nu_{j, X e} / \nu_{j, X e^{+}}}{1+\nu_{j, X e} / \nu_{j, X e^{+}}}\right) \mathbf{u}_{X e} .
\end{aligned}
$$

The first two terms represent flux driven by pressure gradient and electrostatic forces. The third term is the flux driven by drag due to collisions with $\mathrm{Xe}^{+}$ions, and the fourth is the flux due to drag from collisions with Xe neutrals. Previously, the Xe neutrals were assumed to have negligible flow velocities; ${ }^{3}$ however, in this simulation we use the values calculated in the Xe discharge model. ${ }^{12}$ For Ba neutrals, the electric field term is zero. The collision frequency terms are cast in the form of ratios to the dominant interaction. The electron drag term is neglected because of the small electron-to-heavy particle mass ratio.

The ion-ion collision frequency that appears in these equations is given by the standard Coulomb frequency, and the neutral Ba-Xe collision frequency is expressed in terms of a constant scattering cross section, $\sigma_{D}=40 \AA^{2}$, based on diffusion measurements for $\mathrm{Ba}$ in $\mathrm{Xe} .{ }^{13} \mathrm{Ba}^{+}-\mathrm{Xe}$ and $\mathrm{Ba}-\mathrm{Xe}^{+}$ collisions are assumed to have the same cross section.

The continuity equations for $\mathrm{Ba}$ and $\mathrm{Ba}^{+}$can be expressed in terms of these fluxes,

$$
\frac{\partial n_{j}}{\partial t}+\nabla \cdot \boldsymbol{\Gamma}_{j}=\dot{n}_{j}
$$

where $\dot{n}_{B a}=-\dot{n}_{B a^{+}} . \dot{n}_{B a^{+}}$is the rate at which $\mathrm{Ba}^{+}$ions are created by ionization of Ba neutrals and $\dot{n}_{B a}$ is the rate at which neutrals are consumed by ionization reactions. The ionization rate is given by the product of the $\mathrm{Ba}$ atom density and the ionization rate coefficient, $\dot{n}_{B a^{+}}\left(T_{e}\right)=n_{B a} \nu_{B a}^{i z}$. The ionization rate coefficient for $\mathrm{Ba}$ was obtained by integrating $\mathrm{Ba}$ ionization cross sections ${ }^{14}$ over a Maxwellian velocity distribution. The model also employs the ideal gas equation of state. The Ba neutrals and ions are assumed to equilibrate with the Xe atoms and ions, so all heavy particles have a single temperature, $T_{h}$.

The Ba transport model depends on a number of Xe plasma parameters, including the Xe atom and ion densities and heavy particle temperature, which appear in the collision frequencies, the electron density and temperature, which determine the $\mathrm{Ba}$ ionization rate, and the Xe neutral and ion velocity and electric field, which appear in the force terms of the momentum equations. These quantities are taken from a 


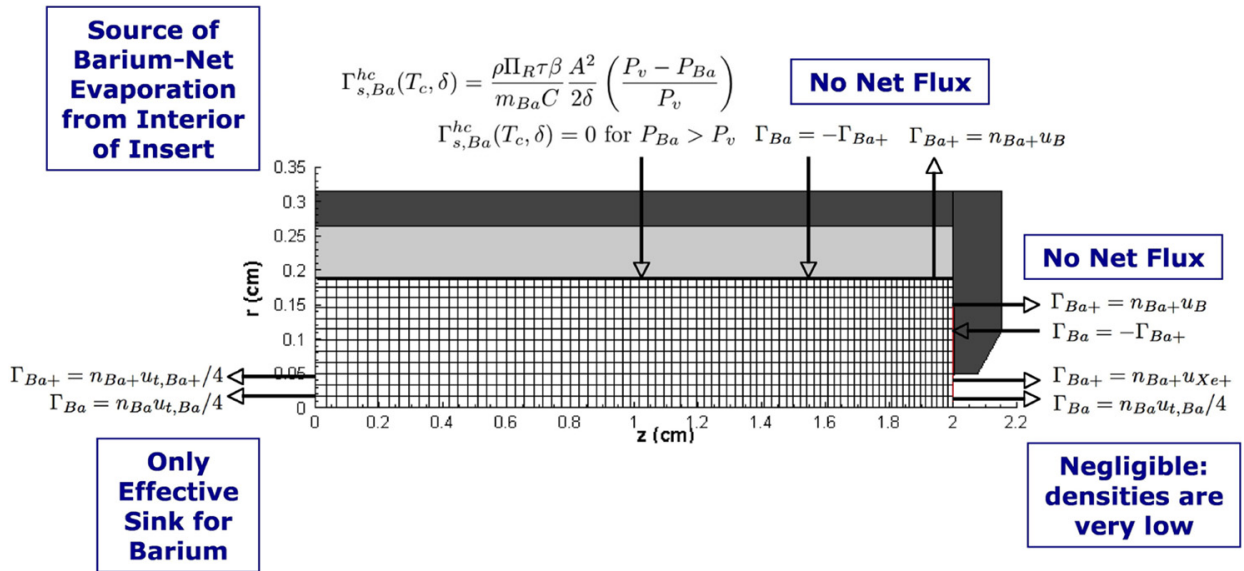

FIG. 4. Boundary conditions and computational grid for the barium transport model. separate simulation ${ }^{12}$ of the Xe plasma and are assumed to be independent of the dynamics of the Ba plasma.

The Xe plasma code was modified to solve a discretized form of Eq. (2) on the 2D axisymmetric computational domain and mesh shown in Fig. 4. This region encompasses the insert plasma at the downstream end of the emitter in the hollow cathode. The Ba neutral and ion densities were initially assumed to be a uniform low value, and the continuity equations were then time-marched until the densities and fluxes achieved steady state values.

\section{B. Boundary conditions}

The simulation domain is bounded by five surfaces as shown in Fig. 4, including the centerline, the upstream inlet to the cathode, the entrance to the cathode orifice, the upstream face of the orifice plate, and the emitter surface. Ion and neutral fluxes through these surfaces are specified as boundary conditions.

The centerline is a symmetry boundary, so the ion and neutral fluxes are set equal to zero. The upstream inlet to the cathode is the only major sink for $\mathrm{Ba}$. Ions and neutrals were assumed to flow out of this surface with their thermal velocities and condense on cooler surfaces upstream, as observed experimentally. ${ }^{5,10}$ The upstream face of the orifice plate was assumed to have a steady-state, submonolayer coverage of $\mathrm{Ba}$ with a net neutral flow from the surface equal to the impinging ion flux. Neutrals were assumed to flow out of the cathode orifice with their thermal velocity. Ions were assumed to have the same velocity at this boundary as the $\mathrm{Xe}^{+}$ions. In practice, there are very few Ba neutrals or ions in this region, so the results are not sensitive to these assumptions.

The emitter surface serves as the source of $\mathrm{Ba}$, which flows from the interior through the porous tungsten. The rate at which $\mathrm{Ba}$ is dispensed depends on insert temperature, $T_{c}$, Ba partial pressure in the insert plasma, $P_{B a}$, and the depth of the reaction front $\delta$, which varies with time. The impregnant decomposition reaction is assumed to be strongly diffusionlimited, so the Ba pressure at the reaction front is very close to the equilibrium pressure of $\mathrm{Ba}$ over the reactants, which is a function of the insert temperature. The diffusive flow or Knudsen flow through the pores and reaction products in the insert is driven by the difference in the pressure at the reaction front and the Ba partial pressure at the insert surface.
Finally, the reaction front recedes into the insert as $\mathrm{Ba}$ is consumed, so the flow resistance increases with time.

The Ba supply rate from the emitter in previous publications $^{3,4,15}$ was based on measurements ${ }^{1}$ of the Ba flux from S-type cathodes in vacuum early in life (with a total operating time $t_{r e f}$ on the order of $10 \mathrm{~h}$ ) scaled by the square root of the operating time. This approach suffered from the uncertainty in the reference time $t_{r e f}$ and because it did not show the dependence of the flux on the depth of the reaction front explicitly. The results presented here are based on an improved Ba flux model which uses depletion depth measurements from dispenser cathodes operating in vacuum. ${ }^{16}$ The depletion depths $\delta$ measured on a number of pellet-shaped dispenser cathodes operated at four different temperatures for various times are plotted in Fig. 5. These cathodes employed the same impregnant as our hollow cathodes, but the tungsten matrix had a porosity $\Pi_{R}$ of 0.185 . The brightness temperatures reported by Roquais ${ }^{16}$ were converted to true temperatures using data from Malter. ${ }^{17}$ These data are well-represented by linear fits of the form $\ln (\delta)=\ln (A)+\frac{1}{2} \ln (t)$, yielding a square root dependence of depletion depth on time

$$
\delta=A t^{1 / 2}
$$

A plot of $\ln \left(A^{2}\right)$ as a function of inverse true temperature also reveals a linear dependence, as shown in Fig. 6. This

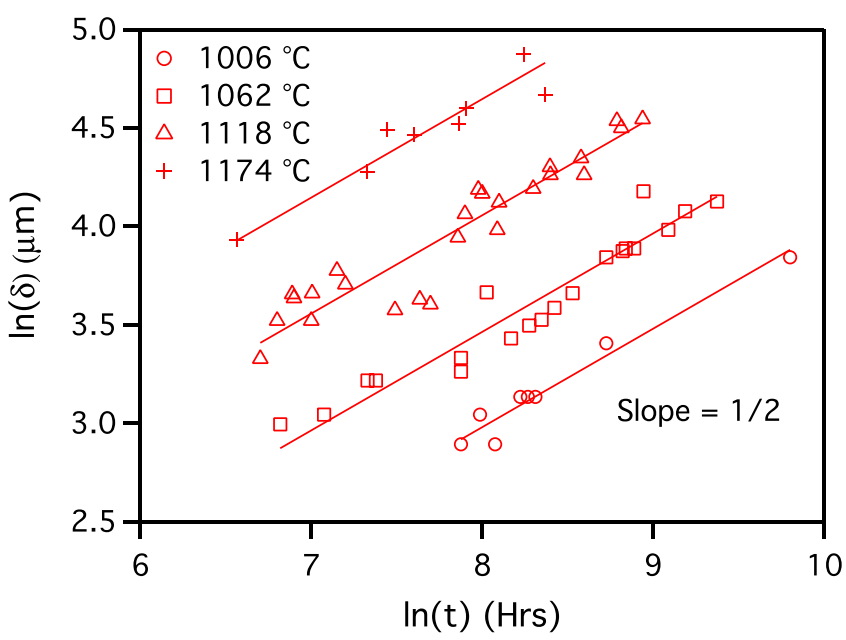

FIG. 5. Measurements of depletion depth as a function of time and temperature for pellet-shaped cathodes operated in vacuum. ${ }^{16}$ 


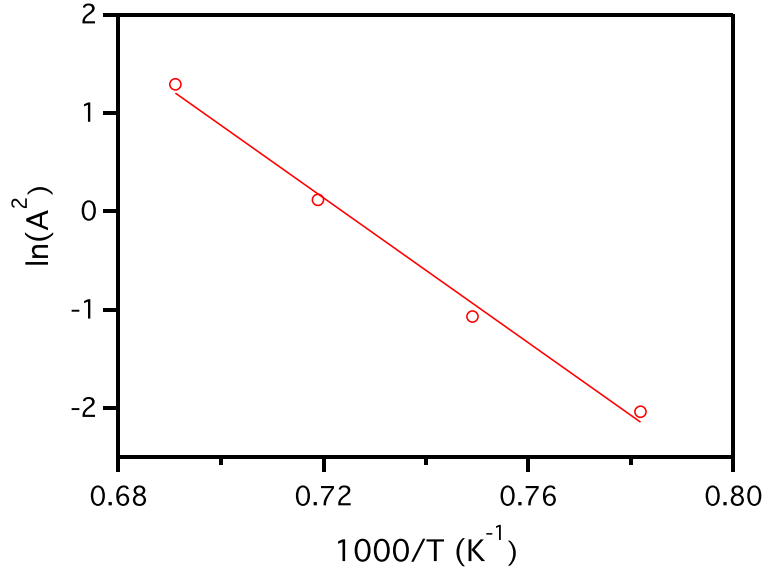

FIG. 6. Variation of the depletion factor plotted as $\ln A^{2}$ with inverse temperature.

gives an Arrhenius-type relationship for the square of the depletion factor $A$,

$$
A^{2}\left(T_{c}\right)=3.749 \times 10^{11} \exp \left(-3.17 e / k T_{c}\right),
$$

where $A$ is in units of $\mu \mathrm{m} / \mathrm{h}^{1 / 2}$ and $T_{c}$ is in $\mathrm{K}$.

The barium vapor flow through the emitter pores is assumed to be Knudsen flow, ${ }^{18,19}$ in which the mean free path for collisions with other gas molecules is much larger than the pore dimensions. The flux of particles through a unit surface determined from kinetic theory ${ }^{20}$ is given by

$$
\Gamma=\frac{4}{3} \lambda(2 \pi m k T)^{-1 / 2} \frac{d P}{d x}
$$

where $\lambda$ is the particle mean free path. Since the tungsten emitter contains a series of pores that may be interconnected, tortuous, and of varying radii, the mean free path is replaced by an effective mean free path, $\lambda_{\text {eff,R, }}$, that accounts for these geometric factors. ${ }^{16}$ Also, the pressure gradient may be approximated as the vapor pressure over the reaction products divided by the depth of the reaction front, assuming that the $\mathrm{Ba}$ partial pressure outside the insert, $P_{B a}$, is zero. Accounting for these considerations, the Ba flux through the pores of Roquais' vacuum cathodes can be written as ${ }^{16}$

$$
\Gamma_{s, B a}^{R}=\frac{4}{3} \frac{\lambda_{\mathrm{eff}, \mathrm{R}}}{\left(2 \pi m_{B a} k T\right)^{1 / 2}} \frac{P_{v}}{\delta} .
$$

The Ba flux from the interior of a hollow cathode can be similarly expressed as

$$
\Gamma_{s, B a}^{h c}=\frac{4}{3} \frac{\lambda_{\mathrm{eff}, \mathrm{hc}}}{\left(2 \pi m_{B a} k T\right)^{1 / 2}}\left(\frac{P_{v}-P_{B a}}{\delta}\right),
$$

where the Ba partial pressure, $P_{B a}$, is no longer negligible and $\lambda_{\text {eff,hc }}$ represents the effective mean free path for the hollow cathode used in this work. The porosity of Roquais' vacuum dispenser cathode is different from the porosity of the hollow cathodes used here, although the substrate and impregnant materials are the same. ${ }^{16}$ Equation (6) can be written as

$$
\Gamma_{s, B a}^{h c}=\frac{\Gamma_{s, B a}^{R}}{C}\left(\frac{P_{v}-P_{B a}}{P_{v}}\right),
$$

where $C=\lambda_{\text {eff,R }} / \lambda_{\text {eff }, \mathrm{hc}}=1.2 .^{16}$

$\Gamma_{s, B a}^{R}$ in Eq. (7) can be expressed in terms of the Ba mass flow rate through the pores as

$$
\Gamma_{s, B a}^{R}=\frac{d m_{B a}}{d t} \frac{1}{m_{B a} S},
$$

where $m_{B a}$ is the mass of a $\mathrm{Ba}$ atom and $S$ is the area of the surface that is emitting barium. The $\mathrm{Ba}$ mass flow rate can be expressed in terms of the $\mathrm{Ba}$ depletion rate, $d \delta / d t$, as

$$
\frac{d m_{B a}}{d t}=\rho S \Pi_{R} \tau \beta \frac{d \delta}{d t},
$$

where $\rho$ is the density of the impregnant, $\Pi_{R}=0.185$ is the porosity of Roquais' cathode, ${ }^{16} \tau$ is the fraction of the pore volume filled with impregnant, $\beta$ is the mass fraction of the impregnant that liberates $\mathrm{Ba}$, and $\delta$ is the $\mathrm{Ba}$ depletion depth. Differentiating Eq. (2) with respect to time yields the rate at which the reaction front receded into the interior in Roquais' experiments,

$$
\left(\frac{d \delta}{d t}\right)_{R}=\frac{A^{2}}{2 \delta} .
$$

Combining Eqs. (7)-(10) gives the Ba flux out of the hollow cathode as

$$
\Gamma_{s, B a}^{h c}=\frac{\rho \Pi_{R} \tau \beta}{m_{B a} C} \frac{A^{2}}{2 \delta}\left(\frac{P_{v}-P_{B a}}{P_{v}}\right) .
$$

Therefore, the flux from the emitter as a function of cathode temperature and depth of the reaction front (depletion depth) is modeled in the code in terms of material properties, Roquais' data on depletion rates over long periods of time, the vapor pressure associated with the dominant Ba-forming reaction, and the $\mathrm{Ba}$ partial pressure in the insert plasma. As Eq. (3) shows, $A^{2}$ is exponentially dependent on temperature. The vapor pressure also varies exponentially with temperature, and in this model is given by the equilibrium pressure, $P_{v}$, in Torr for the impregnant decomposition reaction proposed by Rittner, ${ }^{18}$

$$
\log P_{v}=8.56-20360 / T_{c} .
$$

In cases for which the ambient Ba pressure exceeds the equilibrium pressure, the reaction is assumed to cease. The temperature distribution measured along the axis of an emitter with the same geometry and operating conditions as the LDT cathode ${ }^{21}$ was used in the simulations. The Ba partial pressure in the insert plasma near the emitter surface is calculated as part of the barium Ba solution. The fraction of the pores filled with impregnate $\tau$ is assumed to be 1 . The fraction of impregnate mass that can be lost in the form of $\mathrm{Ba}, \beta=0.39$, is based on Lipeles' and Kan's thermochemical model of the $\mathrm{BaO}-\mathrm{CaO}-\mathrm{Al}_{2} \mathrm{O}_{3}$ impregnant. ${ }^{22}$ The remaining $60 \%$ of $\mathrm{Ba}$ is locked up in $\mathrm{BaAl}_{2} \mathrm{O}_{4}$ and various tungstates, which are stable reaction products. The fraction 
of Ba remaining in the measurements discussed in Section II was about 0.3 (based on comparing the $\mathrm{Ba} / \mathrm{Al}$ ratios in the depleted regions with those in the unreacted regions). The EDS measurements were probably dominated by the signal in the interior of the impregnant-filled pores, which might be primarily monobarium aluminate (with a barium content equal to $1 / 4$ the original value). The tungstates are probably concentrated along the walls of the pores where the $\mathrm{BaO}$ released in impregnant decomposition reacts with the tungsten.

Ba neutrals and ions also flow back to the insert surface. Ions enter the sheath at the Bohm velocity, $u_{B}=\sqrt{k T_{e} / m_{B a}}$, and the ion flux is $\Gamma_{B a^{+}}=n_{B a+} u_{B}$. The cathode temperatures are too high for $\mathrm{Ba}$ to accumulate in thick layers on the surface, and the evaporation rate for bulk $\mathrm{Ba}$ at these temperatures exceeds the ion and neutral fluxes by many orders of magnitude, so we assume that the surface has a steady state, submonolayer coverage of Ba adsorbed on oxygen on tungsten. In steady state, there is no net total $\mathrm{Ba}$ flux to the surface. The neutral flux to the surface is balanced by the desorption of neutrals, and ions that strike the surface return to the plasma as neutral $\mathrm{Ba}$ atoms, so there is a net neutral flow (in addition to the neutral flow from the insert interior) which is equal in magnitude to the ion flow. This assumption is consistent with the observations from long duration tests that $\mathrm{Ba}$ does not accumulate on the downstream surfaces of the inserts. ${ }^{23}$

The orifice plate upstream face was also assumed to have a steady-state, submonolayer coverage with a net neutral flow from the surface equal to the impinging ion flux. Neutrals were assumed to flow out of the cathode orifice with their thermal velocity. Ions were assumed to have the same velocity at this point as the xenon ions. In practice, there are very few barium ions or neutrals in this region, so the results are not sensitive to these assumptions. The upstream boundary is the only major sink for barium. Ions and neutrals were assumed to flow out this surface with their thermal velocities and condense on cooler surfaces upstream, as observed experimentally. ${ }^{5,10}$

\section{The xenon and barium plasma solutions}

The results of the Xe plasma simulation for the cathode at a discharge current of $13.3 \mathrm{~A}$ and a Xe flow rate of 3.7 sccm have been described previously, ${ }^{15}$ but will be briefly summarized here. Figure 7(a) shows the neutral flow field. The neutral density is relatively high $\left(\sim 10^{22} \mathrm{~m}^{-3}\right)$ and drops rapidly in the region near the orifice because of the flow out of the cathode and the consumption of neutrals in the strong ionization zone at the downstream end of the insert. The streamlines reveal two sources of neutral gas: the upstream inlet and the return flow of ions neutralized on the walls. The streamlines from both sources converge on the orifice.

Figures 7(b) and 7(c) show the electron current transport and resultant plasma heating. The streamlines represent the electron current. As Fig. 7(c) shows, the emitter temperature is strongly peaked at the downstream end and electron emission is confined to a region about $4 \mathrm{~mm}$ long near the orifice plate. The electron flow converges on the orifice and resistive heating from the high current density results in a peak in the electron temperature of about $1.85 \mathrm{eV}$ in the orifice. Further upstream, the plasma potential is low and electrons can penetrate from the plasma to the insert surface, resulting in net electron flow to the insert.

The plasma density distribution and resulting ion flow are shown in Fig. 7(d). The high electron temperature near the orifice leads to a peak plasma density of $\sim 10^{21} \mathrm{~m}^{-3}$ at the downstream end. Ions created in this ionization zone flow out radially and upstream, as shown by the ion current streamlines. $\mathrm{Xe}^{+}$ions created here are neutralized on the walls and return to the discharge as neutrals, as shown by the neutral flow streamlines in Fig. 7(a).

The experimental observations indicate that the restructuring of tungsten in the eroded zone alters the permeability, restricting $\mathrm{Ba}$ flow to the surface. Based on the measured depletion depths, we assumed that the pores were completely blocked for the first $2.5 \mathrm{~mm}$ at the downstream end, corresponding to a permeability of zero, and that the permeability varied linearly from zero to unity, corresponding to the flow resistance of an undisturbed region, over the insert from $2.5 \mathrm{~mm}$ to $4 \mathrm{~mm}$ from the tip. The Ba plasma simulation results for beginning of life conditions are shown in Fig. 8. The mean free path for $\mathrm{Ba}$ atom ionization is plotted in Fig. 8(a). These values are based on the $\mathrm{Ba}$ atom thermal velocity and the ionization frequency, which was calculated using the electron density and temperature profiles. The mean free path for ionization upstream of the dense plasma region is on the order of meters, but drops to less than $0.1 \mathrm{~mm}$ near the orifice. Ba atoms that drift into the dense Xe plasma have a high probability of being ionized.

Figure $8(\mathrm{~b})$ shows the neutral $\mathrm{Ba}$ flow field. The $\mathrm{Ba}$ neutral density peaks at $\sim 4.5 \times 10^{16} \mathrm{~m}^{-3}$ near the emitter surface at a point $5-6 \mathrm{~mm}$ upstream of the orifice plate and in the corner between the emitter and the orifice plate. The density decreases by up to two orders of magnitude at the upstream end of the insert and drops to near zero in the ionization zone near the orifice. All Ba neutrals ultimately originate in the insert. $\mathrm{Ba}^{+}$ions are neutralized on the walls and return to the interior as neutrals, providing a second source of neutral gas. There are two sinks for Ba neutral gas-the cold surfaces upstream of the emitter where $\mathrm{Ba}$ condenses and the ionization zone where neutrals are consumed in ionizing reactions. The neutral density is so low near the orifice that the neutral loss rate through the orifice is negligible. The steep neutral Ba density gradient surrounding the ionization zone is sustained by a balance between the pressure gradient and the drag force associated with collisions between $\mathrm{Ba}$ atoms and neutral Xe atoms. ${ }^{3}$

The $\mathrm{Ba}^{+}$ion density and flow streamlines are shown in Fig. 8(c). The $\mathrm{Ba}^{+}$ion density is near zero in the dense Xe plasma near the orifice and peaks in a relatively thin ionization front surrounding that zone. As Figs. 8(a) and 8(b) indicate, neutral $\mathrm{Ba}$ flowing toward the intense Xe plasma is ionized at the periphery. The $\mathrm{Ba}^{+}$ion streamlines show that the ions generated in the ionization zone flow outward and ultimately strike the emitter or the orifice plate, where they are neutralized and re-emitted as Ba atoms. The steady state 

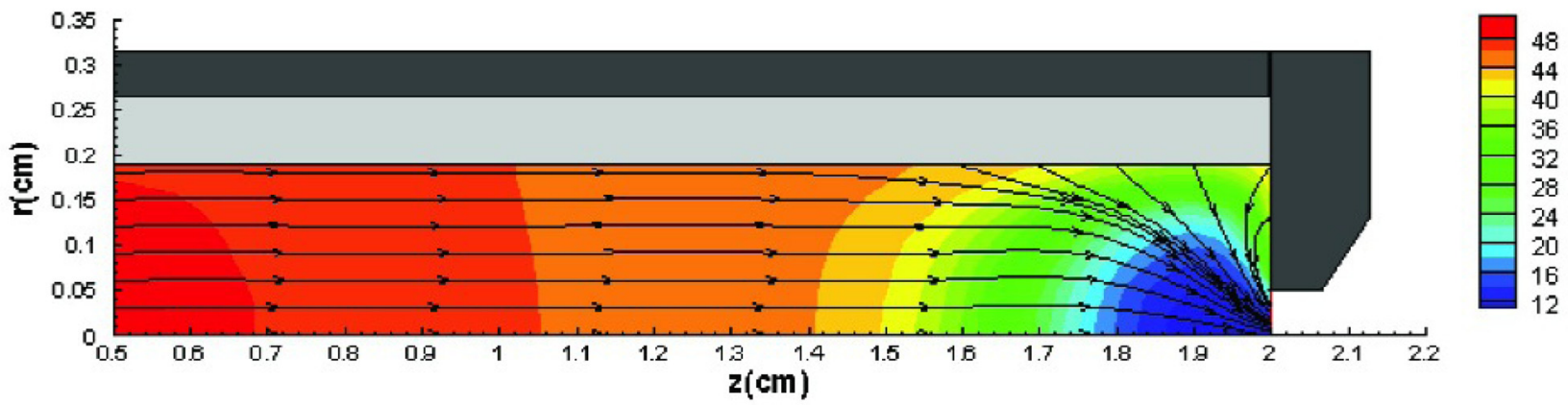

(a) Xenon neutral density contours, $\mathrm{n}_{\mathrm{Xe}} / 10^{21}\left(\mathrm{~m}^{-3}\right)$ and neutral flux streamlines.

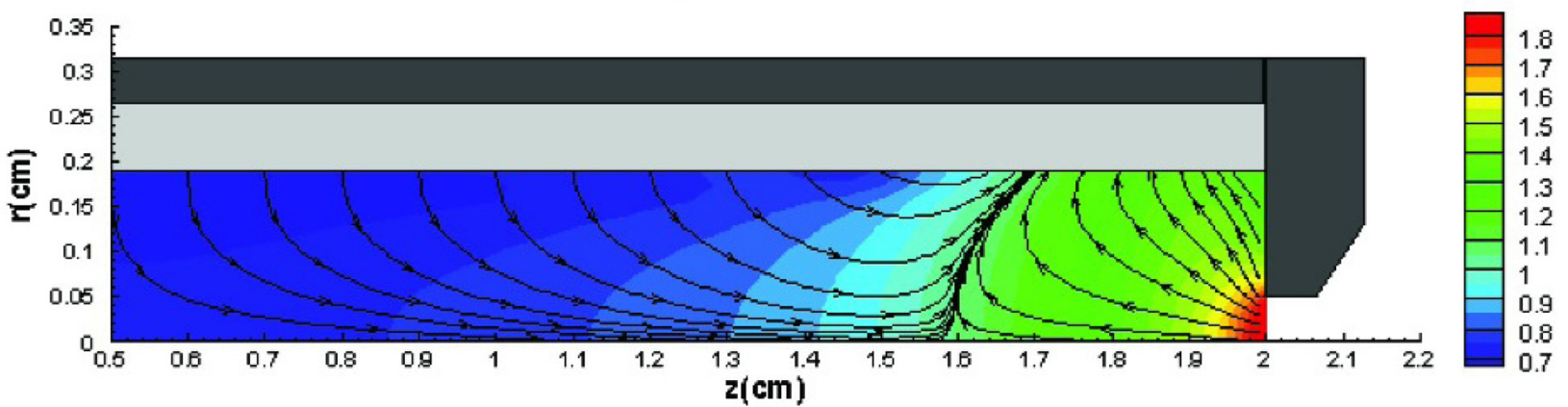

(b) Electron temperature contours $(\mathrm{eV})$ and electron current streamlines.

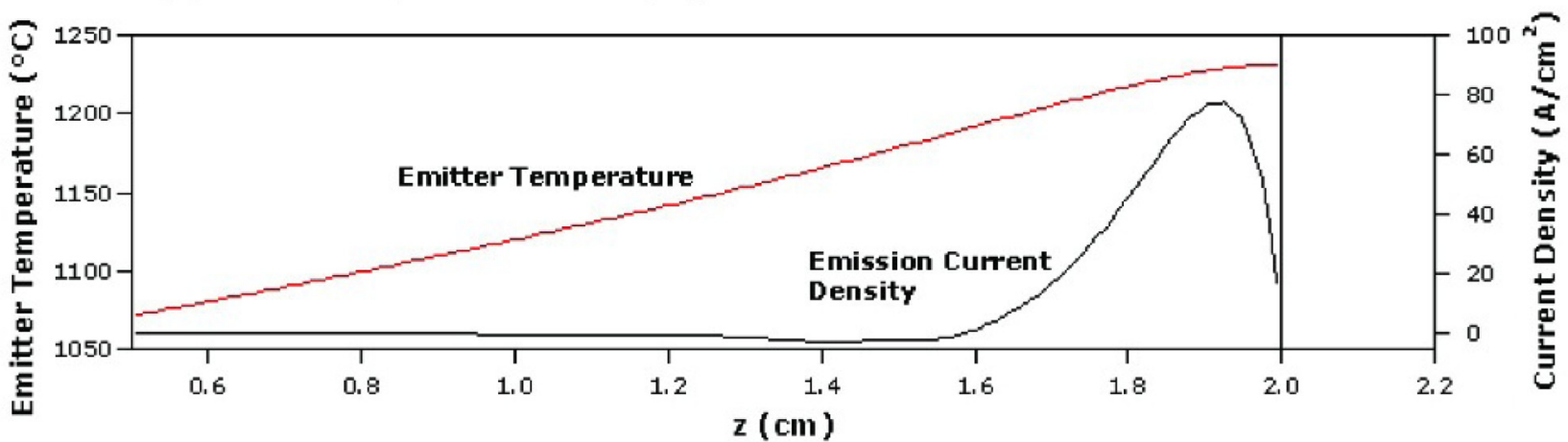

(c) Emitter temperature profile and electron emission current density.

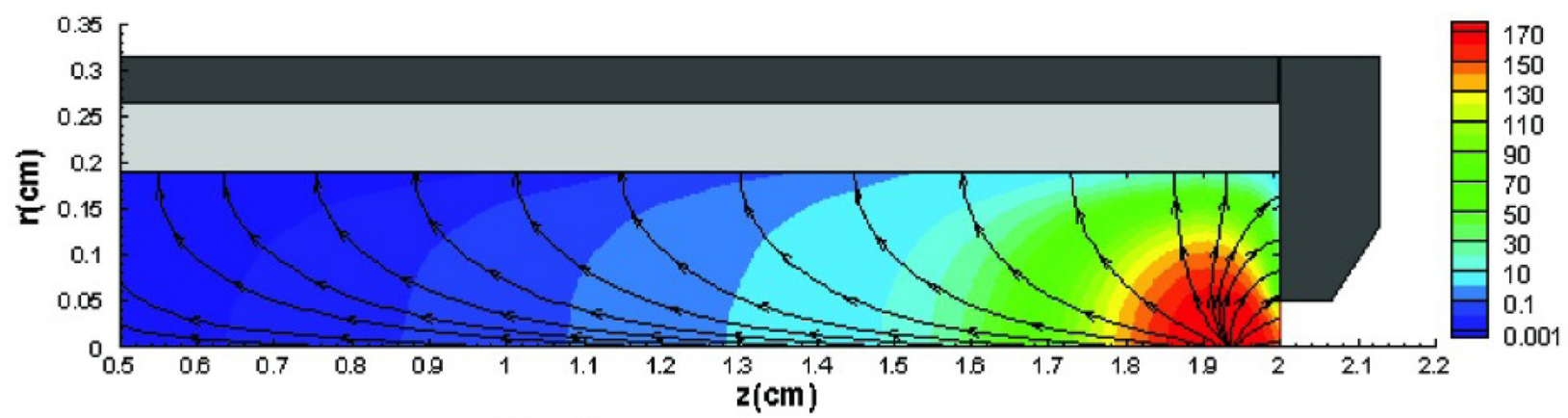

(d) Plasma density, $\mathrm{n}_{\mathrm{e}} / 10^{19}\left(\mathrm{~m}^{-3}\right)$ and ion current streamlines.

FIG. 7. Xenon plasma solution for the discharge hollow cathode at the full power operating point.

$\mathrm{Ba}^{+}$ion density distribution is the result of a more complex balance of forces. ${ }^{3}$

\section{Time dependent simulation of barium depletion}

The Ba plasma model and the flux boundary condition were used to determine how the depletion depth varies in time. We assume that the depletion depth changes slowly in time and that the internal distribution of Ba moves through a series of quasi-steady states, which allows the use of the steady state plasma model to calculate the Ba fluxes from the insert. The depletion calculation starts by specifying the initial depletion depth along the insert $\delta_{0}(z)$, which is a way of representing the flow resistance associated with the porous tungsten structure in the etched region (this is not modeled explicitly). The pores in tungsten are much larger than the pores in the impregnant reaction products, so presumably this flow resistance is relatively low. The initial depth was 


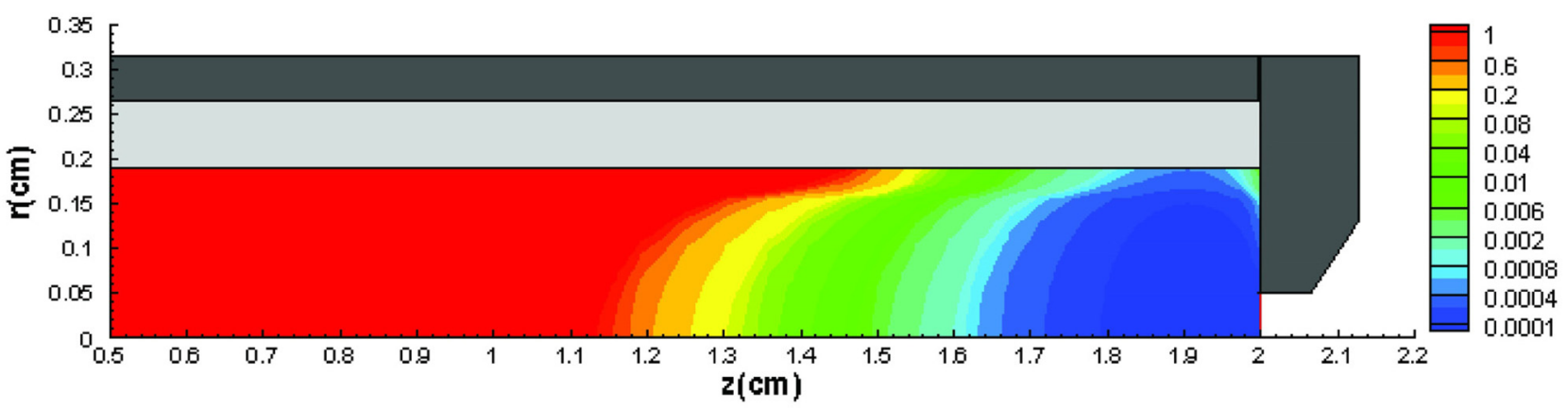

(a) Barium ionization mean free path (m).

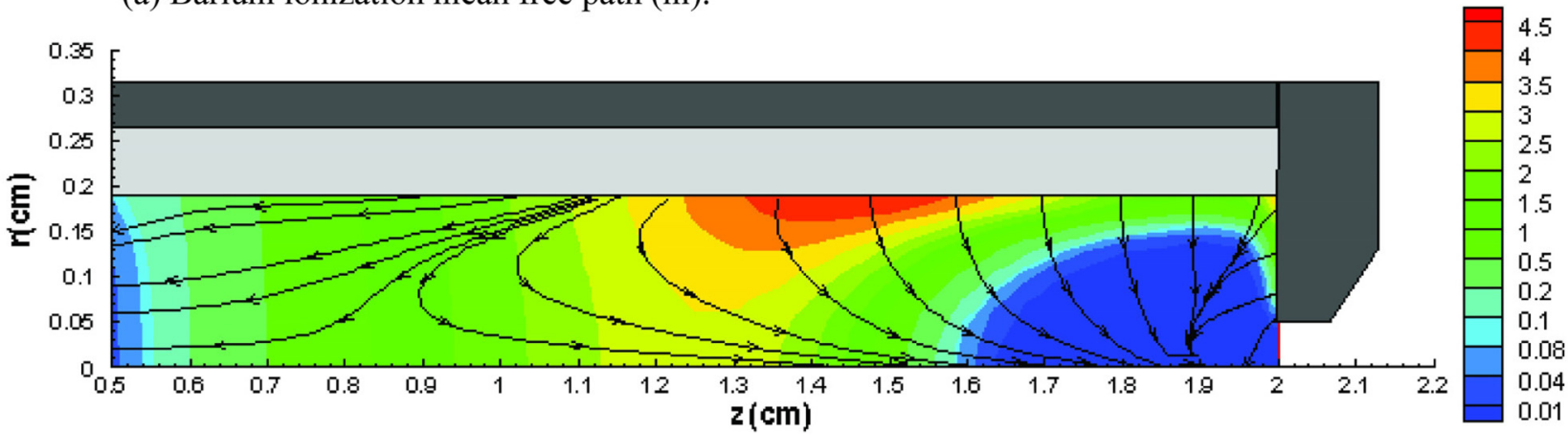

(b) Barium neutral density contours $\mathrm{n}_{\mathrm{Ba}} / 10^{16}\left(\mathrm{~m}^{-3}\right)$ and barium neutral flow streamlines.

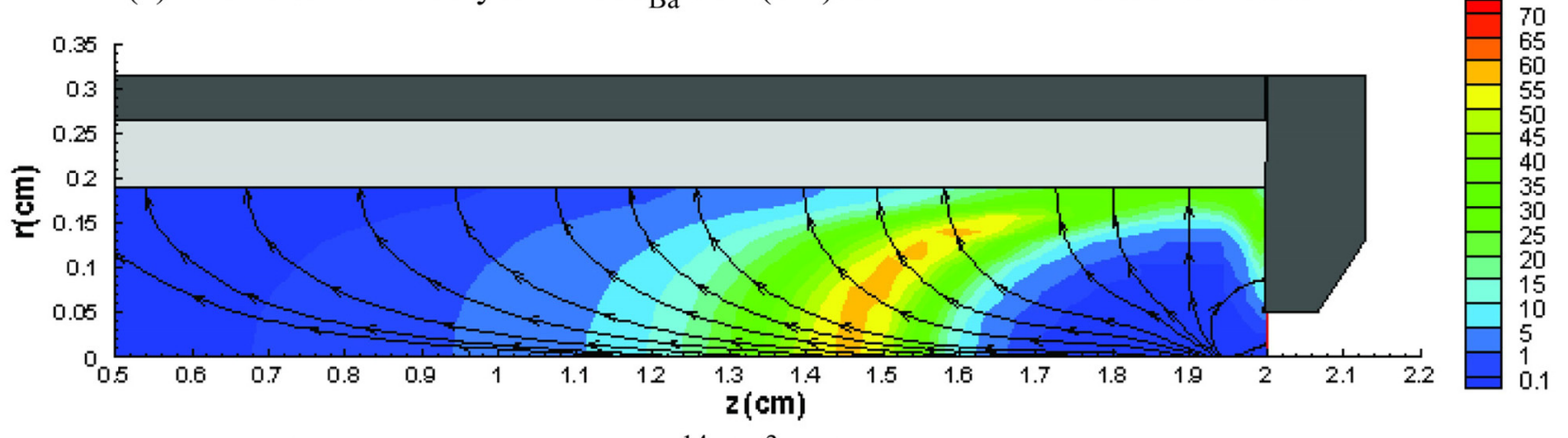

(c) Barium ion density contours $\mathrm{n}_{\mathrm{Ba}+} / 10^{14}\left(\mathrm{~m}^{-3}\right)$ and barium ion flow streamlines.

FIG. 8. Barium plasma solution for the discharge hollow cathode at the full power operating point.

assumed to be $2 \mu \mathrm{m}$, although the final results are not particularly sensitive to this choice.

Next, a steady state simulation of the Ba plasma in the insert was performed using Eq. (11) as the depletion depthdependent emitter flux boundary condition. The velocity of the reaction front into the hollow cathode insert was then integrated to calculate a new profile for the depletion depth. The calculation was then repeated using the new values for the depletion depth profile until a total of $8200 \mathrm{~h}$ had been accumulated. The reaction front velocity at a depth $\delta_{i}$ for step $i$ is given by

$$
\left(\frac{d \delta_{i}}{d t}\right)_{h c}=\frac{\Pi_{R}}{\Pi_{h c}} \frac{1}{C} \frac{A^{2}}{2 \delta_{i}}\left(\frac{P_{v}-P_{B a, i}}{P_{v}}\right),
$$

assuming 1D diffusion of $\mathrm{Ba}$ from the interior. Integrating this expression yields the new depletion depth $\delta_{i+1}$ at a given $z$ location along the insert,

$$
\delta_{i+1}(z)=\left[\frac{\Pi_{R}}{\Pi_{h c}} \frac{A^{2}}{C}\left(\frac{P_{v}-P_{B a, i}}{P_{v}}\right) \Delta t+\delta_{i}^{2}(z)\right]^{1 / 2} .
$$

This assumes that the $\mathrm{Ba}$ partial pressure, $P_{B a}$, does not change significantly over time $\Delta t$. Figure 9 shows the change in the peak $\mathrm{Ba}$ pressure near the emitter surface over the duration of the simulation. Time steps varying from 50 to $1000 \mathrm{~h}$ were chosen to minimize the discretization error.

The results for the measured temperature profile are plotted in Fig. 10. The calculated neutral Ba partial pressure near the emitter is compared to the equilibrium $\mathrm{Ba}$ pressure over the reaction zone in Fig. 10(a). The equilibrium vapor pressure profile follows the cathode temperature profile, increasing monotonically in the downstream direction. The axial neutral pressure distribution first rises in the downstream direction, then drops where the electron density and temperature peak, due to ionization. Although Ba flow from the emitter is set to zero over $2.5 \mathrm{~mm}$ at the downstream end of the insert, the neutral pressure rises again near the orifice plate in a small recirculation zone that is generated in the corner. The ambient Ba pressure initially exceeds the equilibrium vapor pressure over much of the insert length, suppressing the reactions in the interior of the porous tungsten dispenser. 


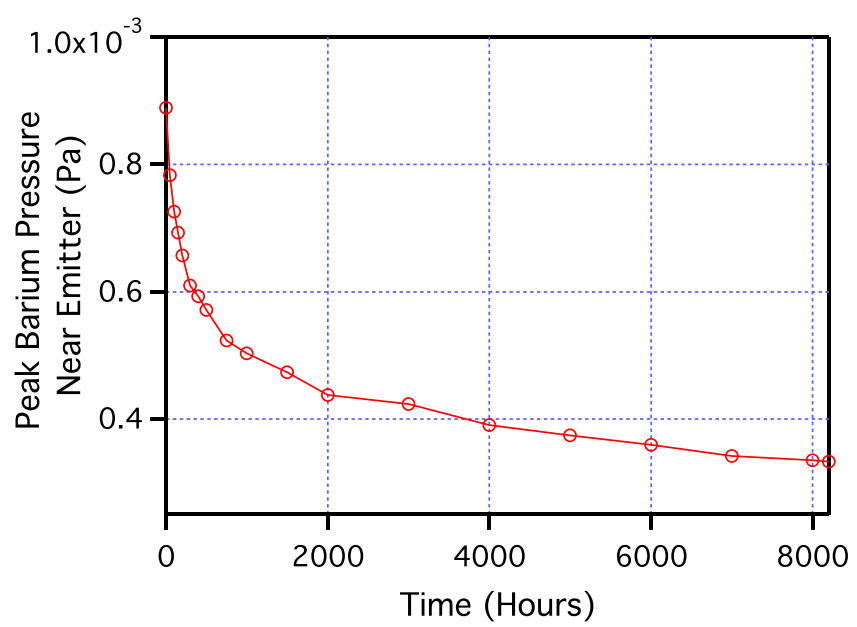

FIG. 9. Decrease in the peak barium partial pressure in the discharge due to depletion for the nominal temperature profile. The open circles represent individual simulations used in the time-dependent depletion calculation.

The decrease in the neutral Ba pressure with time shown in Fig. 10(a) is due to a reduction in the Ba flux from the interior, as shown in Fig. 10(b). The flux initially peaks in the region between 1.6 and $1.75 \mathrm{~cm}$. The distribution broadens with time as the neutral Ba pressure falls below the equilibrium vapor pressure over the reaction front. Some Ba emission also occurs at the upstream end where the partial pressure of $\mathrm{Ba}$ falls below the equilibrium pressure for the reaction.

The recession of the reaction front into the interior with time is displayed in Fig. 10(c). Ba depletion is initially restricted to the narrow region between 1.6 and $1.75 \mathrm{~cm}$, but as more of the surface starts to emit barium, this profile also broadens. The maximum depth predicted for these conditions after $8200 \mathrm{~h}$ of operation is about $130 \mu \mathrm{m}$ just upstream of the region over which $\mathrm{Ba}$ emission is set to zero. Some depletion at the upstream end can also be seen.

\section{COMPARISON OF EXPERIMENTAL AND SIMULATION RESULTS}

The simulation results are compared with the measured depletion depths in Fig. 11. When the Ba partial pressure is equal to zero, Eq. (13) can be integrated over the total operating time to give the total depletion depth. The resulting depletion depth corresponding to operation in vacuum for $8200 \mathrm{~h}$ is plotted as the lower dashed line in Fig. 11. These values are much larger than the measured values, highlighting the importance of the finite Ba pressure in the plasma in suppressing depletion.

The intermediate curve represents the results using the nominal temperature profile. It reproduces qualitatively the shape of the measured curve, with the maximum depletion depth upstream of the region with no $\mathrm{Ba}$ emission and no depletion where the Ba plasma pressure exceeds the equilibrium vapor pressure. This appears to confirm the proposed mechanism-suppression of $\mathrm{Ba}$ production by the high $\mathrm{Ba}$ partial pressure in the discharge. However, the predicted magnitude of the depletion depth is larger than the measured values by a factor of up to 2.5 .

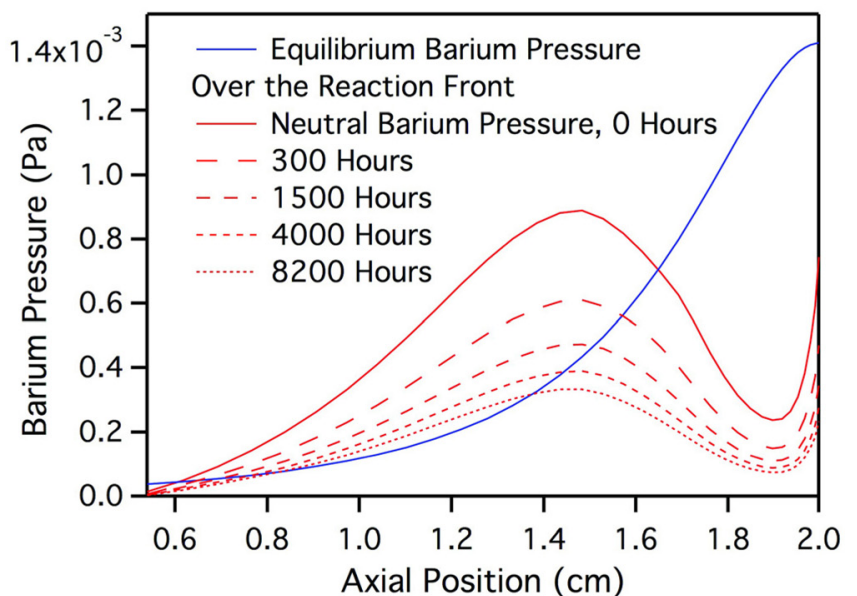

a) Equilibrium barium pressure over the reaction front and profiles of the barium partial pressure in the insert plasma.

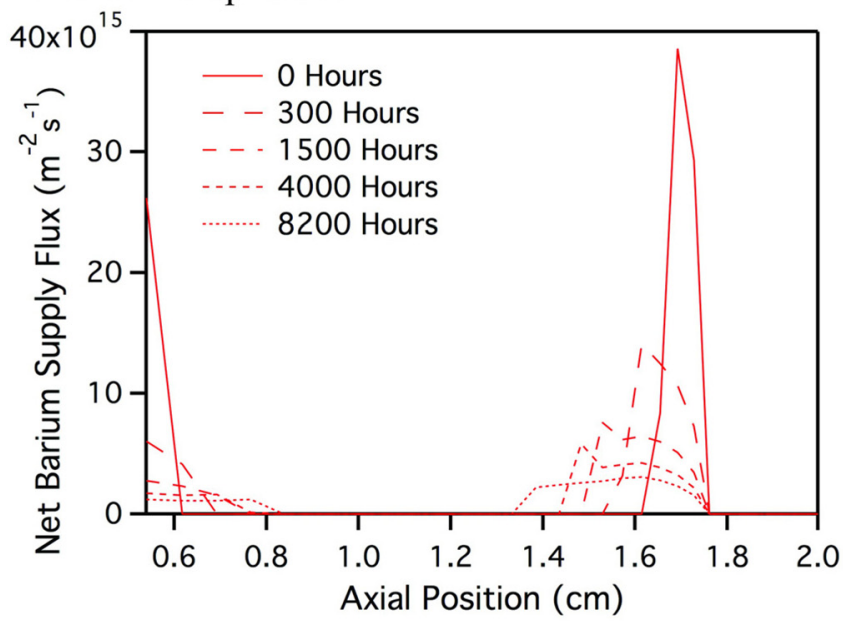

b) Variation in the profile of barium flux from the emitter due to depletion over time.

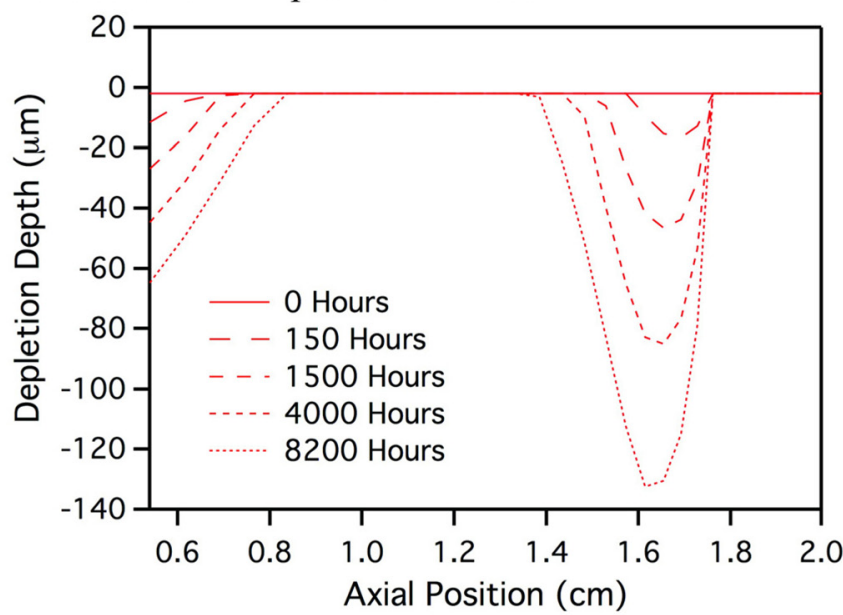

c) Depletion depth as a function of time.

FIG. 10. Results of the time-dependent simulation for the nominal temperature profile.

This discrepancy could be attributed to uncertainties in the equilibrium $\mathrm{Ba}$ pressure for the impregnant reduction reaction, the $\mathrm{Ba}$ flow rates (e.g., the effective porosity of the porous structure), code predictions of the $\mathrm{Ba}$ partial pressure 


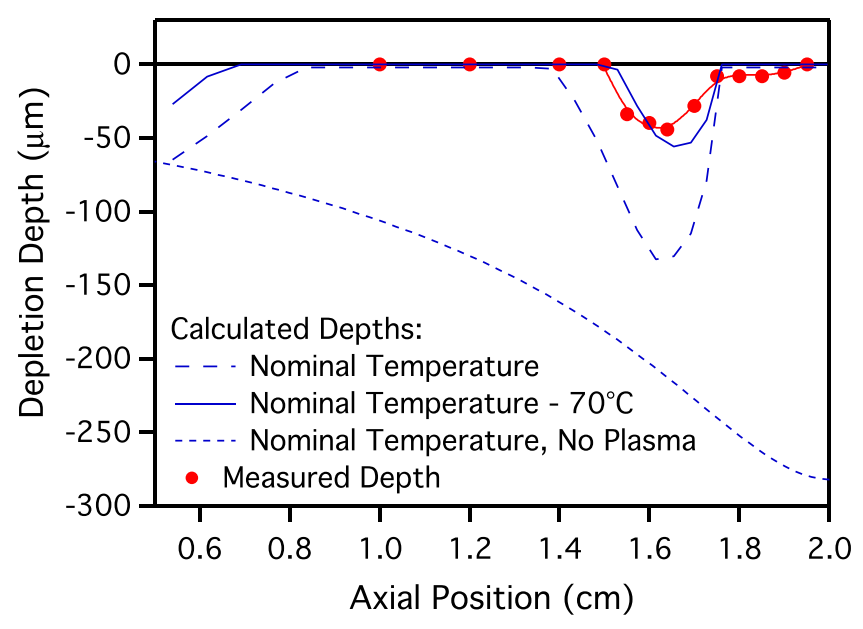

FIG. 11. Comparison of measured depletion depths with simulation results.

in the discharge, or the cathode temperature. Sensitivity analyses indicate that temperature is the only parameter that can realistically account for this difference. If the $\mathrm{Ba}$ flow rate from the interior was actually lower than the model described here would indicate, the magnitude of the depletion depth would be lower. However, lower flow rates also reduce the partial pressure of $\mathrm{Ba}$ in the insert plasma allowing more of the insert to emit $\mathrm{Ba}$ and broadening the depletion depth profile. Conversely, if the actual equilibrium $\mathrm{Ba}$ pressure over the reaction front was lower than that in the model, Ba reactions would be suppressed over an even larger area and the depletion restricted to a narrower zone, but it would not significantly change the magnitude of the depletion depth.

The only parameter that affects both the magnitude of the depletion depth and the width of the profile is the temperature. If we assume that the temperature of the cathode is $70^{\circ} \mathrm{C}$ lower than the measured values, agreement between the model and the depth measurements is very good, as shown by the solid blue line in Fig. 11. The lower temperature reduces the rate of depletion, so the total depletion depth is lower. It simultaneously reduces the equilibrium $\mathrm{Ba}$ pressure over the reaction front, so the reduced $\mathrm{Ba}$ flow and resulting partial pressure in the insert plasma do not cause a broadening of the depletion depth profile. The depletion rate and the equilibrium vapor pressure are both exponentially dependent on the temperature, so a relatively small change in this parameter can explain the discrepancy between the measured and calculated depths. In comparison, other parameters affect the rate and vapor pressure linearly, so much larger changes would have to be postulated to explain the difference.

A $70^{\circ} \mathrm{C}$ error in temperature is larger than would be expected given the uncertainties in the temperature measurements. ${ }^{21}$ However, temperature decreases of this magnitude over a period of several hundred hours have been observed at the beginning of long duration tests. ${ }^{24}$ The temperature decrease is generally attributed to long term conditioning of the emitter surface (removal of reactive contaminants and achieving a stable surface morphology and crystal structure) which results in a decrease in the work function. The temperature measurements obtained in relatively short duration tests, before this conditioning has occurred, may therefore underestimate the steady state temperature reached in the 8200 h test.

\section{CONCLUSIONS}

Measurements of $\mathrm{Ba}$ depletion depths for the cathode operated for $8200 \mathrm{~h}$ revealed that $\mathrm{Ba}$ losses were confined to a small region near the downstream end of the insert, confirming predictions made earlier on the basis of a numerical model of $\mathrm{Ba}$ transport in the hollow cathode plasma. ${ }^{3}$ The narrow depletion depth profile is the result of two effects. First, erosion and subsequent redeposition of tungsten at the downstream end restructure the porous tungsten matrix and reduce the permeability to $\mathrm{Ba}$ flow from the interior. This effect prevents decomposition of the impregnant over the first few $\mathrm{mm}$ of the insert. Second, $\mathrm{Ba}$ is recycled efficiently in the insert plasma, and the $\mathrm{Ba}$ partial pressure is relatively high. Over much of the upstream part of the insert, the $\mathrm{Ba}$ pressure exceeds the equilibrium vapor pressure of the reactants, suppressing the reaction and preventing depletion in those regions.

The first effect is modeled in the code by assigning an ad hoc permeability at the downstream end of the insert, while the second is modeled self-consistently. The code reproduces the depletion depth profile shape very well, but overpredicts the magnitude of the depletion when using temperatures measured in short duration tests of a similar cathode. Excellent quantitative agreement is achieved when the temperature is assumed to be $70{ }^{\circ} \mathrm{C}$ lower. Observations from other long duration tests indicate that a reduced temperature is plausible.

The agreement achieved between the modeling and experiments indicates a significant improvement in our understanding of the physics governing Ba depletion. The model is not yet predictive because it relies on inputs such as the extent of the region over which $\mathrm{Ba}$ flow is blocked by tungsten deposits and is subject to uncertainties in the cathode temperature over long periods of operation. However, even with these uncertainties, Ba depletion in hollow cathodes operated in conditions like those in the $8200 \mathrm{~h}$ test is not expected to be a critical failure mode because of the mechanisms that tend to suppress losses.

\section{ACKNOWLEDGMENTS}

The authors would like to thank Jim Kulleck for his assistance with the scanning electron microscope. The research described in this paper was carried out by the Jet Propulsion Laboratory, California Institute of Technology, under a contract with the National Aeronautics and Space Administration. Reference herein to any specific commercial product, process, or service by trade name, trademark, manufacturer, or otherwise, does not constitute or imply its endorsement by the United States Government or the Jet Propulsion Laboratory, California Institute of Technology.

\footnotetext{
${ }^{1}$ A. Shroff, P. Palluel, and J. Tonnerre, Appl. Surf. Sci. 8, 36 (1981).

${ }^{2}$ T. Sarver-Verhey, in 34th Joint Propulsion Conference, Cleveland, OH (1998), Paper No. AIAA-98-3482.
} 
${ }^{3}$ J. Polk, I. Mikellides, I. Katz, and A. Capece, J. Appl. Phys. 105, 113301 (2009).

${ }^{4}$ J. Polk, I. Mikellides, I. Katz, and A. Capece, in JANNAF 6th MSS/4th LPS/3rd SPS Conference, Orlando, FL (2008), Paper No. JANNAF-SPSIII-45.

${ }^{5}$ J. Polk, J. Anderson, J. Brophy, V. Rawlin, M. Patterson, and J. Sovey, in 35th Joint Propulsion Conference, Los Angeles, CA (1999), Paper No. AIAA-99-2446.

${ }^{6}$ J. Brophy, Rev. Sci. Instrum. 73, 1071 (2002).

${ }^{7}$ J. Polk, D. Brinza, R. Kakuda, J. Brophy, I. Katz, J. Anderson, V. Rawlin, M. Patterson, J. Sovey, and J. Hamley, in 27th International Electric Propulsion Conference, Pasadena, CA (2001), Paper No. IEPC-01-075.

${ }^{8}$ A. Sengupta, J. Brophy, and K. Goodfellow, in 40th Joint Propulsion Conference, Fort Lauderdale, FL (2004).

${ }^{9}$ T. Verhey, in 27th Joint Propulsion Conference, Sacramento, CA (1991), Paper No. AIAA-91-2123.

${ }^{10}$ A. Sengupta, in 29th International Electric Propulsion Conference, Princeton, NJ (2005), Paper No. IEPC 2005-026.

${ }^{11}$ G. Gaertner, P. Geittner, D. Raasch, and D. Wiechert, Appl. Surf. Sci. 146, 22 (1999).
${ }^{12}$ I. Mikellides, I. Katz, D. Goebel, and J. Polk, J. Appl. Phys. 98, 113303 (2005). ${ }^{13}$ T. G. Walker, K. Bonin, and W. Happer, J. Chem. Phys. 87, 660 (1987).

${ }^{14}$ J. Dettmann and F. Karstensen, J. Phys. B: At. Mol. Phys. 15, 287 (1982).

${ }^{15}$ J. Polk, I. Mikellides, A. Capece, and I. Katz, J. Appl. Phys. 115, 183301 (2014).

${ }^{16}$ J. Roquais, F. Poreta, R. le Dozea, J. Ricauda, A. Monterrinb, and A. Steinbrunn, Appl. Surf. Sci. 215, 5 (2003).

${ }^{17}$ L. Malter and D. Langmuir, Phys. Rev. 55, 743 (1939).

${ }^{18}$ E. Rittner, W. Rutledge, and R. Ahlert, J. Appl. Phys. 28, 1468 (1957).

${ }^{19} \mathrm{~A}$. Fote and K. Luey, "Barium transport process in impregnated dispenser cathodes," Technical Report No. SD-TR-81-102, Space Division, Air Force Systems Command, 1982.

${ }^{20} \mathrm{~W}$. Vincenti and C. Kruger, Introduction to Physical Gas Dynamics (John Wiley \& Sons, 1965).

${ }^{21}$ J. Polk, C. Marrese-Reading, B. Thornber, L. Dang, L. Johnson, and I. Katz, Rev. Sci. Instrum. 78, 093101 (2007).

${ }^{22}$ R. Lipeles and H. Kan, Appl. Surf. Sci. 16, 189 (1983).

${ }^{23}$ A. Sengupta, J. Kulleck, N. Hill, and W. Ohlinger, Rev. Sci. Instrum. 79, 111301 (2008).

${ }^{24}$ T. Sarver-Verhey, in 25th International Electric Propulsion Conference, Cleveland, OH (1997), Paper No. IEPC 97-168. 